\title{
TeCme: Tecnologias e Metodologias na Educação em Dispositivos Móveis
}

\author{
Denise Goya ${ }^{1}$, Fabiano Moraes², Ricardo Liang ${ }^{3}$ \\ ${ }^{1}$ Centro de Matemática, Computação e Cognição \\ Universidade Federal do ABC (UFABC) - Santo André, SP - Brazil \\ \{denise.goya, fabiano.moraes, ricardo.liang\}@ufabc.edu.br
}

\begin{abstract}
Resumo. Apresenta-se um aplicativo para dispositivos móveis na plataforma Android. O aplicativo TeCme é um objeto de aprendizagem do tipo curso que explora hipermídias para oferecer uma nova dinâmica na navegação em cursos virtuais, incluindo maior liberdade ao cursista.
\end{abstract}

\section{Cenário de Uso}

Dispositivos móveis como tablets e smartphones alcançaram significativa penetração no mercado nacional [IDC Brasil 2013 e 2014], ao mesmo tempo em que oferecem sofisticados recursos computacionais, como conectividade e processamento de multimídias. No Brasil, a iniciativa federal tem apontado interesse em implantar políticas educacionais relacionadas ao uso de dispositivos móveis nas escolas públicas, a exemplo dos projetos Um Computador por Aluno e Educação Digital - Política para computadores interativos e tablets [MEC 2010 e 2012]. Diante da preocupação em capacitar professores na construção de cursos virtuais usando plataformas móveis, a equipe do Programa Anual de Capacitação Continuada da Universidade Federal do ABC iniciou a adaptação do conteúdo de seus cursos oferecidos na modalidade à distância. A primeira observação realizada foi que as soluções preexistentes para entrega de conteúdos de cursos em Ambientes Virtuais de Aprendizagem para dispositivos móveis são essencialmente textuais, em que até mesmo botões gráficos são dispostos linearmente, induzindo a leitura sequencial de cima para baixo, da esquerda para a direita, caso, por exemplo, do Moodle Mobile (Figura 1). Ao se deparar com a necessidade de melhor explorar os recursos de interatividade por meio de toque e gestos na tela e considerando o tamanho reduzido dos visores, a equipe iniciou $o$ desenvolvimento do TeCme, cujo aplicativo para Android com a oferta do curso “Tecnologias e Metodologias na Educação" é descrito nas subseções a seguir.

$\mathrm{O} \mathrm{TeCme}$ foi concebido para ser oferecido inicialmente para docentes do ensino superior, tutores e coordenadores de polo da Universidade Aberta do Brasil, na modalidade $\mathrm{EaD}$, com o apoio de tutoria para acompanhamento das atividades dos cursistas. 


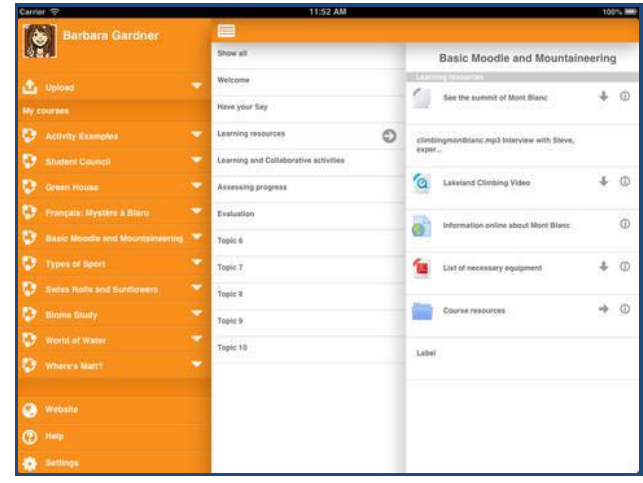

Figura 1. Tela do Moodle Mobile para tablet (Fonte: moodle.org)

\section{Desenvolvimento}

Para o desenvolvimento da primeira versão do TeCme, foi eleito como alvo o sistema operacional Android por este ocupar a primeira posição no mercado de tablets e smartphones [Gartner 2014; IDC Brasil 2013]. Com o objetivo de se explorar recursos de interatividade e movimentos, foi adotado o AndEngine ${ }^{1}$ como complemento ao Android $\mathrm{SDK}^{2}$. O Android SDK é um kit de desenvolvimento de software em Java dedicado para a plataforma Android; o AndEngine é uma biblioteca gráfica para manipulação de objetos $2 \mathrm{D}$, distribuída com código aberto especialmente para $\mathrm{o}$ desenvolvimento de jogos para dispositivos com Android.

O curso "Novas Tecnologias e Metodologias na Educação" já vinha sendo oferecido regularmente em ambiente virtual de aprendizagem com interface Web. Em sua oitava edição, contava com uma estruturação em quatro módulos e onze aulas, numa carga didática de 60 horas. A organização original do curso e parte dos objetos de aprendizagem (textos e vídeos, em grande maioria) foram preservados na adaptação para oferta do curso em tablets. Uma das estratégias adotadas pela equipe durante a criação da nova interface com o usuário foi a elaboração de hipermídias gráficas, a partir das quais ambientes pudessem ser explorados pelo cursista. A metáfora que se empregou foi a de um corredor de salas, onde cada sala guarda conteúdos de uma aula. Diferentes layouts de sala indicam diferentes módulos do curso. Objetos de aprendizagem adicionais foram produzidos, com o intuito de conferir melhor adequação do conteúdo aos dispositivos móveis: novos vídeos e animações foram criados e, para ampliar a sensação de presença, realizaram-se gravações em áudio dos roteiros de aula.

A intenção com a produção de novos objetos multimídia foi aumentar o envolvimento dos cursistas ao interagirem com o conteúdo por meio da tela de toque. Outra mudança significativa foi a ruptura da linearidade do curso: antes as aulas necessariamente se seguiam sequencialmente, da primeira à última aula. Após uma revisão de requisitos, constatou-se que a dependência dos conteúdos não era estritamente sequencial, ou seja, para se assistir à quarta aula não era obrigatória a conclusão da terceira, por exemplo. Optou-se, então, por conceder maior liberdade ao

\footnotetext{
${ }^{1} \mathrm{http}: / /$ www.andengine.org/

${ }^{2} \mathrm{http}: / /$ developer.android.com/sdk
} 
cursista, permitindo que ele fizesse escolhas sobre em quais salas entraria primeiro, desde que já tivesse cumprido os requisitos para adentrar nelas. Para tanto, criou-se um artifício para que o aluno pudesse espiar dentro das salas, sem entrar.

A metodologia que guiou o desenvolvimento do TeCme foi a INTERA Inteligência, Tecnologias Educacionais e Recursos Acessíveis [Braga et al 2013] que identifica a necessidade de uma equipe multidisciplinar com profissionais empenhando papéis como: analista, conteudista, demandante, gerente de projetos, designer de interface, designer instrucional, designer técnico, equipe de desenvolvimento e equipe de teste. A metodologia estabelece que a elaboração de objetos de aprendizagem se dê de forma iterada e interativamente, passando pelas etapas: contextualização, requisitos, arquitetura, desenvolvimento, testes e qualidade, disponibilização, avaliação, gestão de projetos e controle de ambiente.

Atualmente, o aplicativo encontra-se na fase de testes e qualidade, onde ajustes de funcionalidade e usabilidade são identificados e demandados. Nova avaliação pedagógica se faz necessária, dado que novos objetos foram inseridos, muitos textos foram reescritos e a navegação, alterada. A aplicação e avaliação do TeCme devem ocorrer brevemente, no próximo oferecimento aos cursistas. Espera-se com a nova concepção de curso um aumento da motivação e engajamento dos cursistas, com consequente queda na evasão e maior atratividade para outros cursos. Possibilitar que o cursista trace seu próprio rumo no desenrolar do curso é muito relevante, pois o aprendiz sente-se motivado ao assumir a responsabilidade pelo próprio aprendizado [Zepke et al 2010].

\section{Apresentação do software}

A atual versão do aplicativo TeCme depende da existência de conexão com internet e acesso ao ambiente virtual de aprendizagem onde o cursista é registrado. Para a Mostra de Software, foi criada uma versão reduzida de demonstração, na qual o conteúdo de apenas duas salas está disponível e a conexão com internet não é necessária.

O TeCme inicia-se com um vídeo de abertura, com uma animação dentro de um elevador que está em movimento, que sugere que o aluno está se deslocando para o $5^{\circ}$ andar da Universidade e logo em seguida a porta do elevador se abre para o corredor de salas. O passeio pelo corredor se dá com um toque de deslizar na tela, para a esquerda ou direita. Os cartazes na porta, ao serem tocados, exibem uma visão geral do que há na sala.

A permissão para entrar em cada sala é sinalizada pela iluminação. A luz acessa significa que o cursista tem permissão para entrar e assistir a aula, ou seja, acessar todo seu conteúdo (Figura 2); a luz reduzida significa que a aula já foi assistida e poderá ser revisitada a qualquer momento (Figura 3); a luz apagada, que o aluno não tem permissão de entrar na sala e a porta está trancada (Figura 4). 


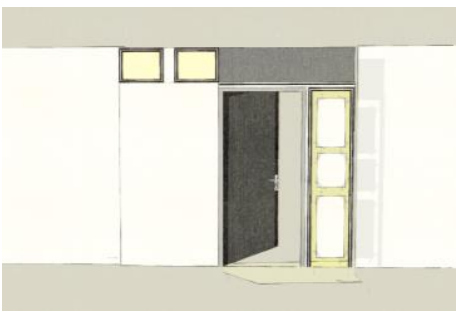

Figura 2 - Sala acesa

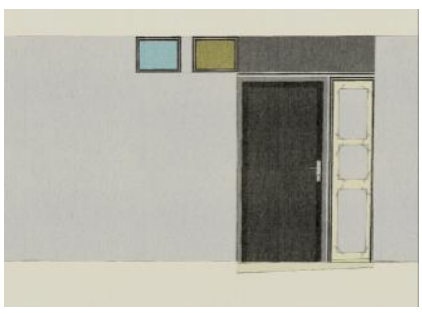

Figura 3 - Sala à meia-luz

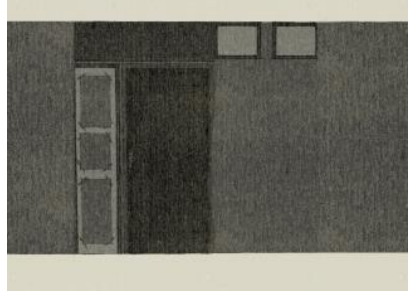

Figura 4 - Sala apagada

Na primeira execução do aplicativo, todas as salas estarão trancadas e escuras, com exceção da porta mais à esquerda, restando apenas a ação de espiar as aulas, em suas respectivas janelas. Ao tocar nessa primeira porta, o aluno poderá perceber a animação audiovisual do toque, indicando que a porta está aberta e "entrará" na sala. Dentro da sala, o aluno poderá observar que há apenas um quadro negro e uma cadeira vazia, que serve de convite para o aluno clicar no quadro e assistir o vídeo de instrução sobre o curso e como utilizar seus recursos. Ao executar ou assistir todo o vídeo, a segunda porta se iluminará indicando que poderá ser aberta e que a primeira aula do curso poderá se iniciar.

Ao se tocar a porta correspondente à primeira aula, continuará a interação do aplicativo. A próxima cena acontece dentro de uma sala de aula. O layout das salas é diferente para cada módulo do curso, mas todas possuem sete objetos em comum: lousa, caixa de som, papel/caderno, ícone de play, computador, botão de apoio e interfone (Figura 5). Além de cumprirem uma função estética, esses objetos funcionam como signos indicadores das ações de cada recurso da aula. Para acessá-los, basta tocar o objeto que deseja e uma breve animação audiovisual indicará o toque e a seleção deste objeto. Todos esses objetos serão descritos detalhadamente a seguir.
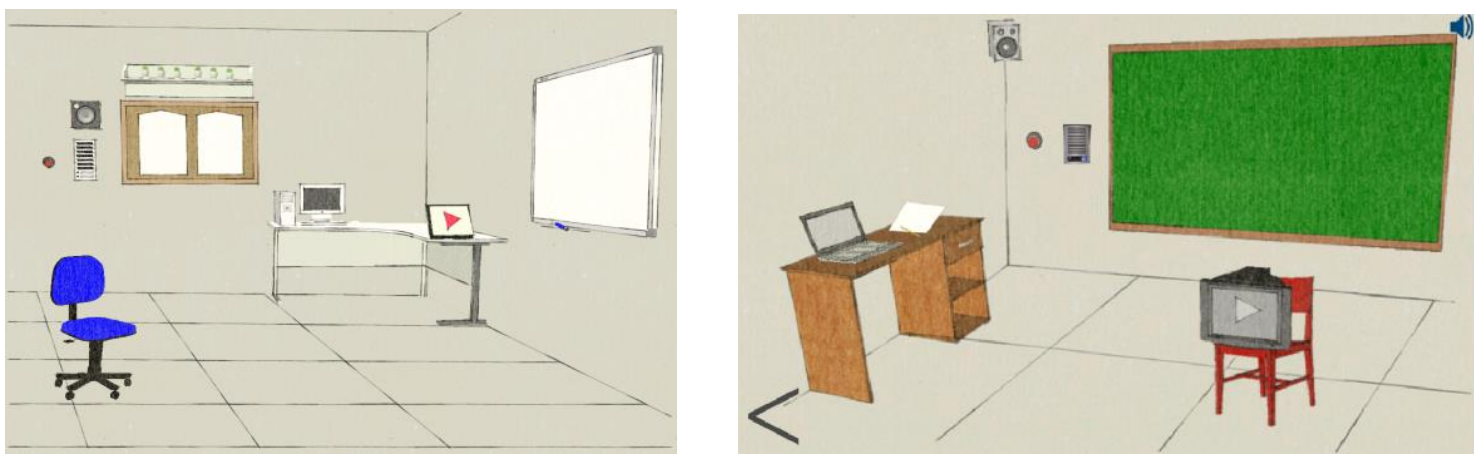

Figura 5 - Exemplos de layout de sala: cada desenho indica um módulo do curso 


\section{Caderno, Papel ou Bloco de Notas}

O Caderno, Papel ou Bloco de Notas tem como objetivo oferecer leituras de textos durante a aula. Estes arquivos podem ser divididos em sessões como forma de organizar seus estudos. As leituras vão desde textos obrigatórios para as aulas, explicação da própria aula, tutoriais, leituras complementares, etc. A navegação é simples: basta o aluno tocar o título do texto deseja, e o leitor de arquivos será aberto para a leitura do seu documento. Caso possua muitos arquivos, a tela poderá ser deslizada para alcançar o restante. A barra de rolagem à direita da tela informa quando será possível deslizar a tela à procura de mais itens.

\section{Caixa de Som ou Alto-falante}

Ao tocar a Caixa de Som, o aluno ligará a Caixa de Som e iniciará o áudio da aula. O áudio será tocado enquanto o aluno estiver navegando dentro dos recursos da mesma sala. Para desligar a Caixa de Som, basta clicar novamente no ícone ou sair da sala.

\section{Botão Play}

O ícone Play possui funcionalidade semelhante à do Caderno: ao tocá-lo será aberta uma nova tela com as sessões e os títulos, neste caso, dos vídeos. As sessões ajudam a separar os vídeos no sentido de organização dos conteúdos. Ao tocar nos títulos, inicia-se a reprodução do vídeo automaticamente.

\section{Computador}

O Computador ou notebook dá acesso às atividades que devem ser entregues no AVA que dá suporte ao curso. As atividades devem ser submetidas no AVA, que possui uma página específica para cada curso. $\mathrm{O}$ aplicativo direciona o usuário diretamente à atividade requisitada, por meio do navegador do dispositivo. Basta fazer o login com seu Usuário e Senha e realizar a atividade.

\section{Lousa}

A lousa possui um formato diferente dos objetos anteriores. Nela, o aluno pode ver o sumário das atividades da aula e usufruir de sua principal função: o checklist das atividades para verificação de pendências de tarefas não realizadas. Sempre que o aluno concluir uma leitura, vídeo ou atividade, ele poderá registrar na lousa, para ter um controle e lembrete do que precisa ser realizado ou já foi realizado. Além do objetivo de controle, a lousa também tem como propósito o gerenciamento do destrancamento das portas das aulas restantes, seguindo os pré-requistos de cada aula. Ou seja, ao se assinalar como realizadas todas as atividades de uma aula, são destrancadas as portas correspondentes às aulas que a necessitam como pré-requisito. 


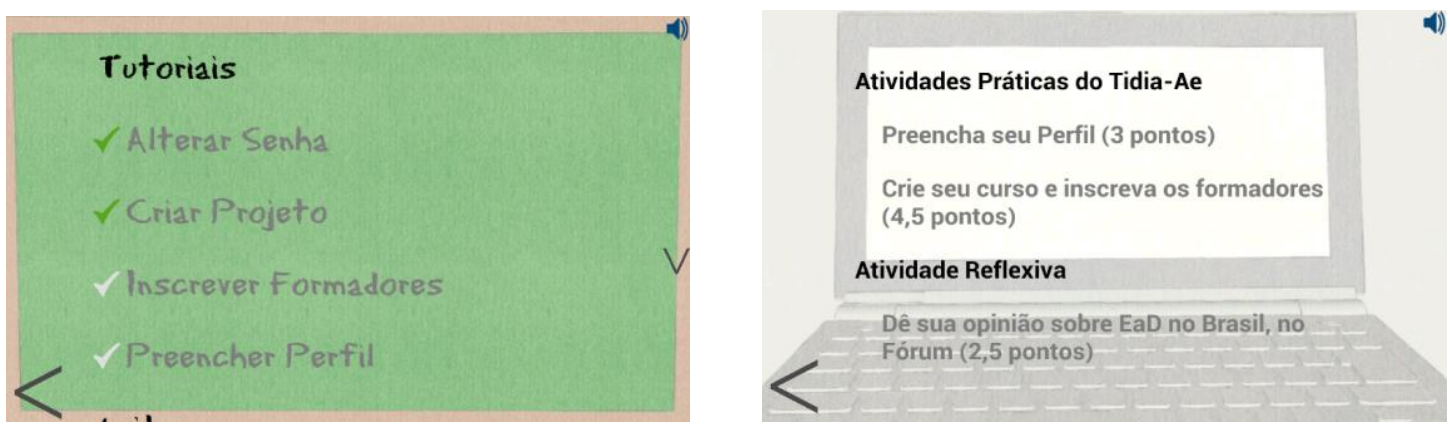

Figura 6 - Lousa e computador: exemplos de recursos dentro das salas

\section{Botão de Emergência e Interfone}

O botão de emergência e o interfone são as opções de ajuda que o aluno pode, eventualmente, necessitar. Enquanto o botão de emergência (ou botão de apoio) traz opções prontas para o aluno, como apoio pedagógico (um documento de guia do cursista, o cronograma do curso, mapa de atividades, critérios de avaliação) e apoio técnico (requisitos para funcionamento e execução simulada do aplicativo em PCs); o Interfone oferece a ajuda com a comunicação direta com os tutores e os colegas de classe, por meio do AVA e do grupo do curso em uma rede social.

\section{Considerações finais}

O aplicativo TeCme é um objeto de aprendizagem do tipo curso para acompanhamento de atividades em dispositivos móveis com Android. A contribuição pedagógica que se espera do software é aumento da motivação e engajamento dos cursistas, com consequente queda na evasão e maior atratividade para outros cursos do Programa Anual de Capacitação Continuada. Cursos em EaD com tutoria tipicamente são lineares e pouco flexíveis; pretende-se avaliar também a influência desse fator.

O aplicativo TeCme é produto de um sistema maior de criação de cursos para dispositivos móveis. Nesta Mostra de Software foi apresentada apenas a interface com o cursista, com uma instância de curso que versa sobre tecnologias para a educação. A plataforma TeCme possui também uma interface com o professor conteudista para construção de cursos, isto é, para seleção dos objetos de aprendizagem que compõem o curso. Na Figura 7, há uma visão geral da arquitetura do sistema. 


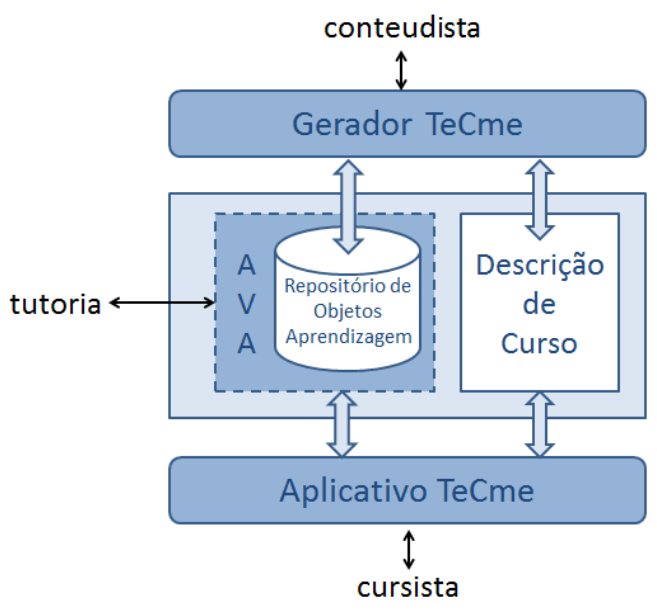

Figura 7 -Arquitetura geral do TeCme: o Aplicativo é a interface com o cursista

\section{Referências}

Braga, J. C.; Pimentel, E.; Dotta, S. (2013) "Metodologia INTERA para o desenvolvimento de Objetos de Aprendizagem". In: XXIV Simpósio Brasileiro de Informática na Educação.

IDC Brasil. (2013) "Estudo da IDC revela explosão de vendas de smartphones no Brasil no segundo trimestre de 2013", http://www.idcbrasil.com.br/ releases/.

IDC Brasil. (2014) "Tablets superam notebooks em vendas pela primeira vez, segundo estudo da IDC", http://www.idcbrasil.com.br/releases/.

Gartner. (2014) "Gartner Says Worldwide Tablet Sales Grew 68 Percent in 2013, With Android Capturing 62 Percent of the Market", http://www.gartner.com/newsroom/id/2674215.

MEC. (2010) "Na rede pública, tecnologia atende 24 milhões de alunos", http://portal.mec.gov.br/.

MEC. (2012) "Ministério distribuirá tablets a professores do ensino médio", http://portal.mec.gov.br/.

Zepke, N.; Leach, L.; Buttler, P. (2010) "Student Engagement: What Is It and What Influences It?" Crown. 